\title{
Hepatocyte growth factor regulates proliferation and differentiation of epithelial monolayers derived from islets of postnatal rat pancreas
}

\author{
R Wang ${ }^{1,2}$, N Yashpal $^{1}$, F Bacchus ${ }^{1}$ and $\mathbf{J}$ Li $^{1}$ \\ ${ }^{1}$ Department of Physiology and Pharmacology, Lawson Health Research Institute, University of Western Ontario, London, Ontario, Canada \\ ${ }^{2}$ Department of Medicine, Lawson Health Research Institute, University of Western Ontario, London, Ontario, Canada \\ (Requests for offprints should be addressed to R Wang, Child Health Research Institute, $5^{\text {th }}$ Floor, 8000 Commissioners Road East, Room A5-146, London, \\ Ontario N6C 2V5, Canada; Email: rwang@uwo.ca)
}

\begin{abstract}
Hepatocyte growth factor (HGF) has been suggested to be a potent regulator of $\beta$-cell function and proliferation. The purpose of this study was to investigate whether HGF could regulate the proliferation and differentiation of islet-derived epithelial monolayers into insulin-producing cells. We have generated islet-derived epithelial monolayers that are enriched with cells expressing c-Kit, a tyrosine kinase receptor and putative marker, from isolated postnatal rat islets. Monolayers were cultured on type I collagen gel and treated in defined differentiation medium with or without HGF $(50 \mathrm{ng} / \mathrm{ml})$ for 7 days. Subsequently, the expression of transcription factors and pancreatic endocrine cell markers as well as c-Kit expression were compared between the HGF $\left(\mathrm{HGF}^{+}\right)$, no HGF treatment $\left(\mathrm{HGF}^{-}\right)$and monolayers without differentiation medium (control) groups, using immunocytochemical and RT-PCR approaches. We observed that the number of c-Kit-, glucose transport type 2 (Glut2)- and the transcription factor pancreatic duodenal homeobox-1
\end{abstract}

(PDX-1)-expressing cells were significantly increased in the $\mathrm{HGF}^{+}$group. The expression of insulin at the mRNA and protein level was also increased in this treatment group with a 1.7-fold increase in basal insulin release and a $2 \cdot 3$-fold increase in insulin content in comparison with the $\mathrm{HGF}^{-}$group. A high proliferative capacity was also found in the $\mathrm{HGF}^{+}$group. Co-localization of insulin and PDX-1 or Glut2 was revealed frequently in cells treated with $\mathrm{HGF}^{+}$with occasional co-staining of c-Kit and insulin observed. This study showed that HGF can activate the proliferation and differentiation of islet-derived epithelial monolayer into insulin-producing cells. However, no formation of islet-like clusters was observed. Taken together, this study implies that HGF mediates differentiation of immature cell types into insulin-expressing cells; however, HGF supplementation alone is insufficient in restoring full $\beta$-cell function.

Journal of Endocrinology (2004) 183, 163-171

\section{Introduction}

Hepatocyte growth factor (HGF) is a mesenchymederived large multifunctional polypeptide paracrine growth factor. It exerts its effects through the heterodimeric transmembrane tyrosine kinase receptor, c-met, and has pleitropic effects, inducing different cellular responses such as cell survival, cell proliferation, migration and differentiation (Gherardi \& Stoker 1991, Zarnegar \& Michalopoulos 1995, Wang et al. 2003). HGF in the pancreas is produced in pancreatic mesenchyme-derived cells and in islet cells. Previous studies have shown that HGF and its receptor are expressed preferentially in a specific spatial and temporal pattern in which maximal HGF and c-met expression correspond to a period of rapid proliferation and development of the endocrine and exocrine compartments, highlighting their role in pancreatic development (Beattie et al. 1996, Calvo et al. 1996).

Both in vivo and in vitro studies have demonstrated that HGF functions as an insulinotropic factor and promotes $\beta$-cell proliferation and regeneration of fetal and adult islets (Otonokoski et al. 1994, 1996, Hayek et al. 1995, Beattie et al. 1996, Gahr et al. 2002). In vitro, HGF has been shown to increase insulin content and proliferation of islets. In addition, intraperitoneal injection of HGF or exogenous HGF gene introduction in mouse models of diabetes has been shown to mitigate hyperglycemia (Nakano et al. 2000, Dai et al. 2003). Furthermore, transgenic mice that over-express HGF in islets are resistant to the diabetogenic effects of the $\beta$-cell toxin streptozotocin (Garcia-Ocana et al. 2001), and $\beta$-cell proliferation, islet cell mass and 
hypoglycemia are increased. Thus it is speculated that HGF not only preserves $\beta$-cell mass but also protects pancreatic $\beta$-cells from destructive death, promotes $\beta$-cell proliferation and preserves insulin production. Finally, HGF alone or in combination with activin $\mathrm{A}$ is also able to induce the transdifferentiation of the amylase-secreting pancreatic acinar AR42J cells into insulin-producing cells (Mashima et al. 1996, 1999), suggesting that HGF may also be a $\beta$-cell differentiation factor.

Cell-based therapeutics such as islet cell transplantation offer a promising approach to the treatment of diabetes. However, for such therapies to be feasible a better understanding of the role of peptide growth factors such as HGF in the regulation of mature $\beta$-cell function and differentiation are necessary. Several studies have shown that it is possible to convert an acinar to duct cell phenotype from the pancreas of different species (Hall \& Lemoine 1992, Arias \& Bendayan 1993) or an acinar to islet cell phenotype under the influence of HGF (Mashima et al. 1996); however, the possibility of HGF influencing the change in phenotype from a ductal to islet cell type is limited.

It is well documented that islets in vitro become senescent, lose their function or, under certain conditions, transdifferentiate (Beattie et al. 1996, 2002). Our previous studies showed that islet isolation results in a loss of islet-matrix interactions, stability and the in vitro transdifferentiation of islets, with a loss of islet hormone expression and the concomitant up-regulation of cytoskeletal proteins characteristic of duct epithelial cells (Wang et al. 2001). Although these studies reveal the plasticity of islet cell phenotype, little is known of the factors or the potential to transform the epithelial phenotype back into an islet one. Our more recent study showed that these cytokeratinexpressing monolayers are enriched with cells that express markers of potential islet precursors such as the wellknown hematopoietic stem cell marker c-Kit. Under the appropriate trophic support, we previously described that these c-Kit-expressing cells can differentiate and reexpress insulin (Wang et al. 2004, Yashpal et al. 2004). Given HGF's role in $\beta$-cell differentiation and function in islets, the present study has examined the potential of HGF to mediate the differentiation of islet-derived epithelial monolayers into insulin-producing cells. We hypothesized that supplementation of HGF might provide a novel strategy for increasing insulin-positive cells in vitro and regulate the differentiation of new islet cell formation.

\section{Material and Methods}

\section{Tissue culture}

Timed pregnant Wistar rats were obtained for the isolation of islets on postnatal day 7 (Charles River, Quebec, Canada). All protocols were approved by the Animal Care
Committee at the University of Western Ontario, and were in accordance with the guidelines of the Canadian Council on Animal Care. Rat pancreata were dissected and islet isolation was carried out as described previously (Wang et al. 2004). To promote epithelial monolayer formation, freshly isolated islets were placed on type I collagen gel and cultured in Dulbecco's modified Eagles's medium (DMEM)/F12 (17.6 mM glucose; GIBCO, Burlington, ON, Canada) serum-free medium supplemented with transferrin $(10 \mu \mathrm{g} / \mathrm{ml})$, insulin $(1 \mu \mathrm{g} / \mathrm{ml})$, and epidermal growth factor $(10 \mathrm{ng} / \mathrm{ml})$ (Sigma, St Louis, MO, USA) (Bonner-Weir et al. 2000, Wang et al. 2001). The cells of the epithelial monolayers, which had no detectable expression of endocrine hormones were subcultured into two experimental groups: an HGF-treated $\left(\mathrm{HGF}^{+} ; 50 \mathrm{ng} / \mathrm{ml}\right)$ (ID Laboratory Inc. London, ON, Canada) and a non-HGF-treated $\left(\mathrm{HGF}^{-}\right)$group cultured on type I collagen with a modified DMEM/F12 as a defined differentiation medium which contained $6.3 \mathrm{mM}$ glucose and 5\% fetal bovine serum (FBS) for a week (Wang et al. 2004). The epithelial monolayers cultured in DMEM/F12 serum-free medium served as a control group. Cultures were maintained in $95 \%$ air $/ 5 \% \mathrm{CO}_{2}$ at $37^{\circ} \mathrm{C}$, and the medium was renewed on alternate days. After 7 days of differentiation in culture, cells and medium were collected for the following investigations.

\section{Immunofluorescence and orphometric analysis}

Cells from $\mathrm{HGF}^{+}, \mathrm{HGF}^{-}$and control groups were fixed in situ with 4\% paraformaldehyde (Wang et al. 2004) and immunostained using immunofluorescence, as described previously (Yashpal et al. 2004). The antibodies used in this study were as follows: mouse anti-human insulin and glucagon, mouse anti-5-bromo-2'-deoxyuridine (BrdU; Sigma), rabbit anti-c-Kit (Santa Cruz Biotechnology, Santa Cruz, CA, USA), rabbit anti-Glut2 (Chemicon, Temecula, CA, USA) and rabbit anti-pancreatic duodenal homeobox-1 factor (PDX-1; a gift from Dr C Wright, University of Vanderbilt, Nashville, TN, USA). The sections were incubated overnight at $4{ }^{\circ} \mathrm{C}$ with the appropriate dilution of primary antibody. To evaluate cell proliferation, cells from all three groups were incubated with $10 \mu \mathrm{M}$ BrdU for $4 \mathrm{~h}$ at $37^{\circ} \mathrm{C}$, followed by immunostaining for BrdU (Wang et al. 1994, 2004). To identify co-expression of phenotypes in both $\mathrm{HGF}^{+}$and $\mathrm{HGF}^{-}$ groups, double immunofluorescence staining was performed. Double-labeled images were recorded by a Lecia DMIRE2 fluorescence microscope with the Openlab image software (Improvision, Lexington, MA, USA). Negative controls included the omission of the primary antibodies or secondary antibody. No staining was observed under the negative control conditions.

The number of cells expressing endocrine hormones, as well as c-Kit, PDX-1 and Glut2, and the BrdU-labeling index was determined using a Lecia DMIRE2 microscope 
connected to computer-assisted image analysis software (Openlab version 1.3). The percentage of expression cells was determined by counting, at least 1000 cells for each experimental group was repeated six times. The data are expressed as a percentage of the total number of cells counted. Data are expressed as means \pm S.E.M. and compared using a Student's $t$-test, with differences considered to be statistically significant when $P<0 \cdot 05$.

\section{Measurement of insulin secretion}

Insulin content and basal insulin release from $\mathrm{HGF}^{+}$, $\mathrm{HGF}^{-}$and control groups were measured using a rat insulin ELISA kit (DRG Diagnostic Inc. Mountainside, NJ, USA). The insulin content within the cells from each experimental group was determined and normalized to the DNA content and expressed as ng/ $\mu \mathrm{g}$ DNA (Wang \& Rosenberg 1999). Glucose responsiveness of insulinexpressing cells from both the $\mathrm{HGF}^{+}$and $\mathrm{HGF}^{-}$groups was examined using an acute glucose challenge, as described previously (Wang \& Rosenberg 1999).

\section{RT-PCR}

Total RNA was extracted at the end of the experiment using the RNAqueous-4 PCR kit (Ambion, Austin, TX, USA). cDNAs were synthesized from $2 \mu \mathrm{g}$ total RNA using oligo(dT) with the SuperScript First Strand Synthesis System (Invitrogen, Burlington, ON, Canada). Subsequent PCR was carried out in a Bimetra Tgradient (Montreal Biotech Inc., Montreal, QC, Canada) for 33 cycles. The following PCR oligonucleotide primers were used: (1) for insulin: forward-5'-TCACACCTG GTGGAAGCTC-3', reverse-5'-ACAATGCCACGCT TCTGC-3' (28 cycles); (2) for glucagon: forward-5'ATGAACGAGGACAAGCGC-3', reverse-5'-TTCAC CAGCCAAGCAATG-3'; (3) for c-Kit (rat): forward5'-AGCAAGAGTTAACGATTCCGGAG-3', reverse5'-CCAGAAAGGTGTAAGTGCCTCCT-3'; (4) for PDX-1: forward-5'-GGTGCCAGAGTTCAGTGCTA3', reverse-5'-TTATTCTCCTCCGGTTCTGC-3'; (5) for Neurogenin 3 (Ngn3): forward-5'-TGGCGCCT CATCCCTTGGATG- ${ }^{\prime}$, reverse- $5^{\prime}$-CAGTCACCC ACTTCTGCTTCG-3'; and (6) $\beta$-actin: forward-5'GACGGGGTCACCCACACTGTGCCCATCTA-3', reverse-5'-CTAGAAGCATTTGCGGTGGACGATGG AGG-3' (28 cycles). The amplified products were analyzed on $1.5 \%$ agarose gels and visualized by ethidium bromide staining. The amount of PCR products generated was quantified by densitometric scanning of band intensities and normalized to the levels of the housekeeping gene $\beta$-actin using the Syngenetool gel analysis software (Syngene version 3.0, Cambridge, Cambs, UK) and expressed as relative expression units (Yashpal et al. 2004).

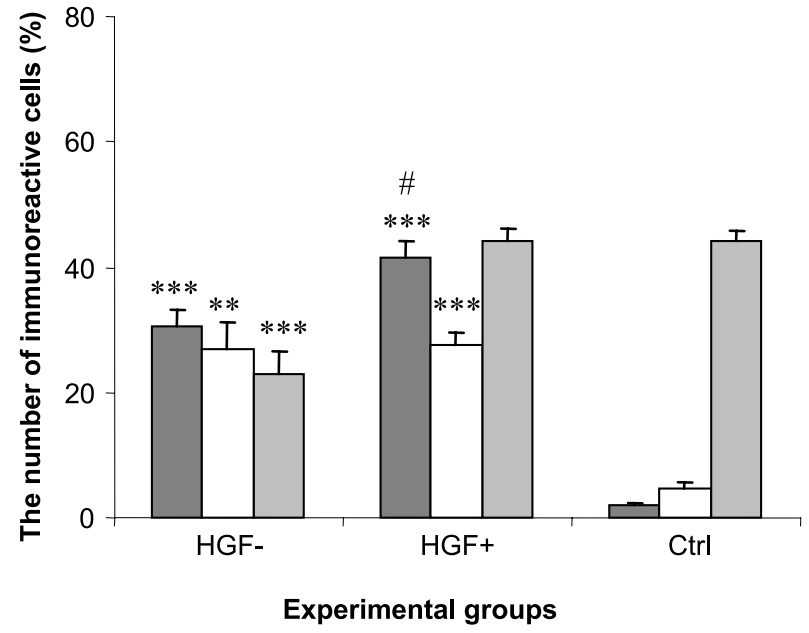

Figure 1 Quantitative analysis of insulin (shaded bars)-, glucagon (open bars)- and c-Kit (dotted bars)-immunoreactive cells in epithelial monolayers cultured with $\mathrm{HGF}\left(\mathrm{HGF}^{+}\right)$or without HGF $\left(\mathrm{HGF}^{-}\right)$and control monolayers (Ctrl) on a type I collagen matrix for a week. Date are given as means \pm S.E.M. ${ }^{* *} P<0 \cdot 01,{ }^{* * *} P<0 \cdot 001$

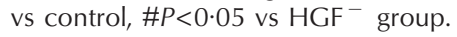

\section{Results}

Effect of HGF on differentiation of epithelial monolayers into pancreatic endocrine cell phenotypes

Previously we found that freshly isolated islets from postnatal day 7 cultured islets on type I collagen gel form epithelial monolayers that lack expression of islet hormones and express immature cell phenotypes such as c-Kit (Wang et al. 2001, 2004). Therefore, we examined the effect of HGF supplementation on the differentiation of islet-derived epithelial monolayers and evaluated differentiation through immunocytochemical staining for insulin and glucagon. In the control group, the epithelial monolayers contained only a few insulin- and glucagon-positive cells with the percentage being $1 \cdot 2 \pm 0 \cdot 5 \%$ and $4 \cdot 1 \pm 1 \%$ respectively (Fig. 1). On the other hand, monolayers treated with supplemented 5\% FBS plus HGF ( $\mathrm{HGF}^{+}$group) had a significant increase in the proportion of insulin- and glucagon-expressing cells with a 35-fold increase in the percentage of insulin (42 $\pm 3 \%)$ - and a 7 -fold increase in the percentage of glucagon $(28 \pm 2 \%)$ immunoreactive cells compared with control monolayers $\left(P<0 \cdot 001\right.$; Figs 1 and 2). In the $\mathrm{HGF}^{-}$group, a significantly high proportion of insulin- $(P<0.001)$ and glucagon-immunopositive cells $(P<0 \cdot 01)$ were present in comparison with the percentage of control monolayers with $31 \pm 2 \%$ insulin-expressing cells and $27 \pm 4 \%$ glucagon-expressing cells (Figs 1 and 2). Both the $\mathrm{HGF}^{+}$ and $\mathrm{HGF}^{-}$groups had no islet-like clusters present (Fig. 2). In the $\mathrm{HGF}^{+}$group, there was no change in the expression of c-Kit $(44 \pm 2 \%)$, and a significant 2-fold decrease in the percentage of c-Kit-expressing cells was 

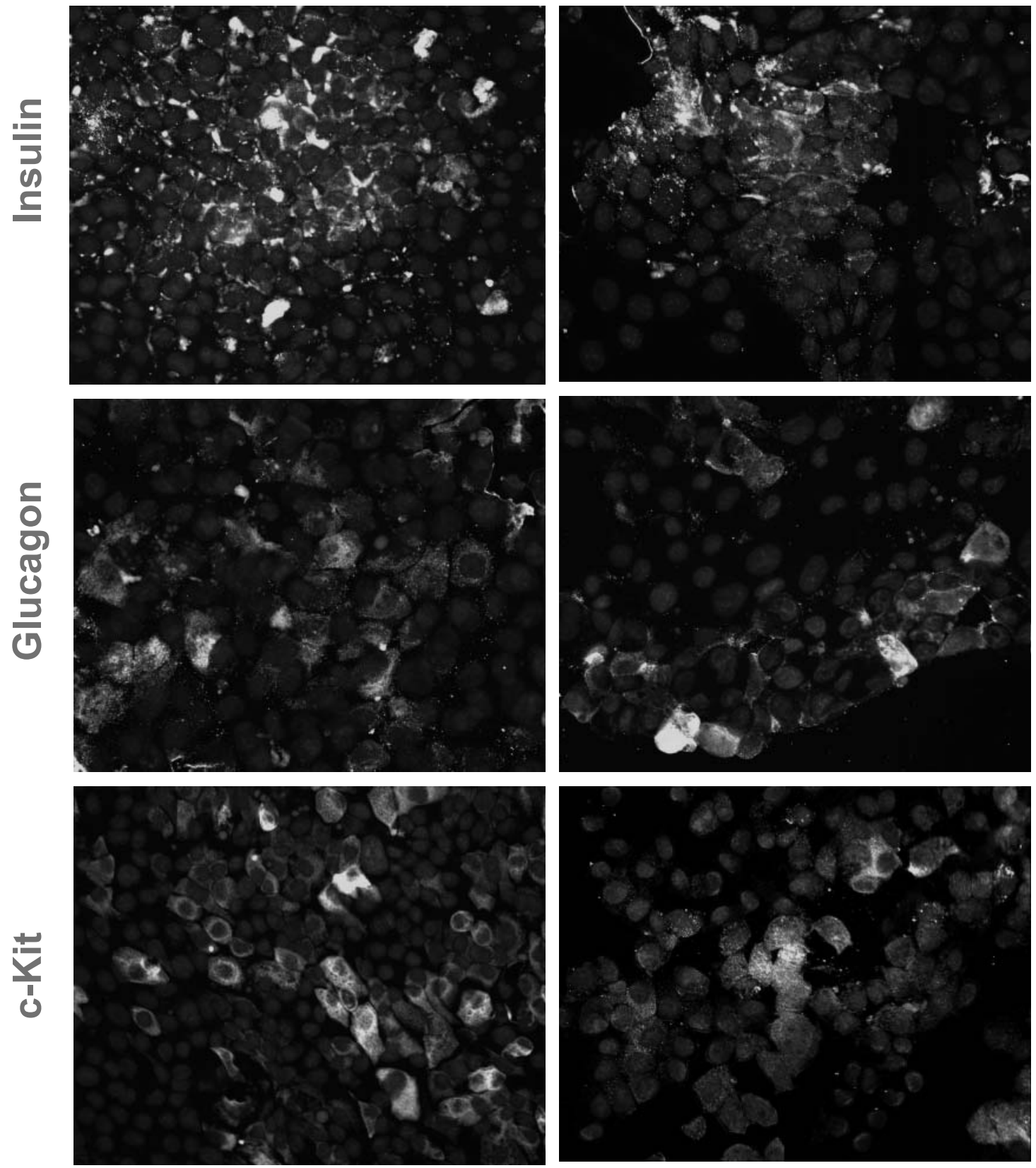

HGF+ group

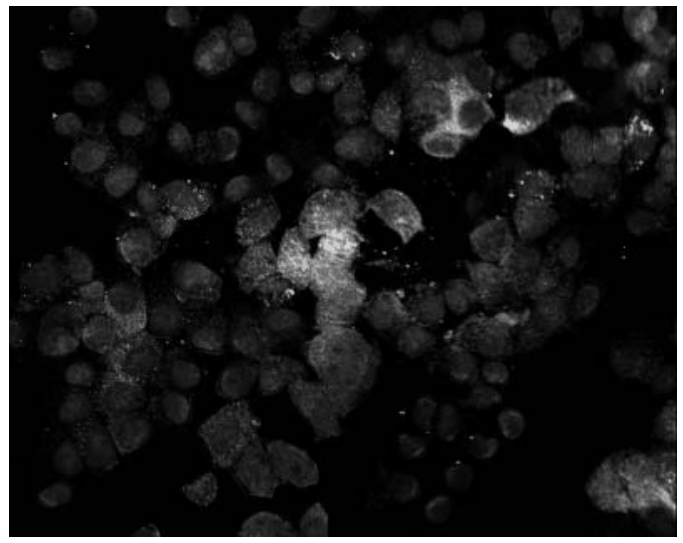

\section{HGF-group}

Figure 2 Immunofluorescent analysis for insulin-, glucagon- and c-Kit-expressing cells fluorescein isothiocynate (FITC) in epithelial monolayers cultured with HGF $\left(\mathrm{HGF}^{+}\right)$or without $\mathrm{HGF}\left(\mathrm{HGF}^{-}\right)$for a week. Nuclei were counterstained by DAPI. Original magnification $\times 400$.

observed in the $\mathrm{HGF}^{-}$group (23 $\left.\pm 3 \%\right)$ compared with the expression of $\mathrm{c}-\mathrm{Kit}$ in the control monolayers (Fig. 1; $P<0 \cdot 001)$.

Both PDX-1 and Glut2 are normally expressed in mature $\beta$-cells and are associated with early endocrine cell development (Pang et al. 1994, McKinnon \& Docherty
2001). To delineate the morphometric changes in the expression of PDX-1 and Glut2, and their linkage to the HGF stimulation, we examined the number of cells expressing PDX-1 and Glut-2 in both the $\mathrm{HGF}^{+}$and $\mathrm{HGF}^{-}$groups (Fig. 3). In a defined differentiation medium, the addition of HGF resulted in a 1.5- and 2-fold 


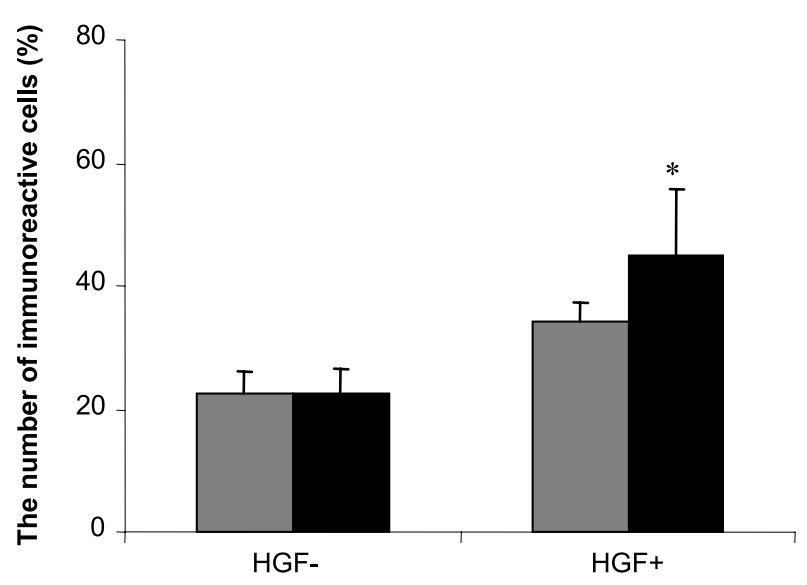

Experimental groups

Figure 3 Quantitative analysis of PDX-1 (hatched bars)- and Glut2 (solid bars)-expressing cells in both $\mathrm{HGF}^{+}$and $\mathrm{HGF}^{-}$groups cultured on a type I collagen matrix with defined differentiation medium for a week. Date are given as means \pm S.E.M. ${ }^{*} P<0 \cdot 05$.

increase in the number of PDX-1- and Glut2-expressing cells compared with the group with no HGF supplementation (Fig. 3; $P<0 \cdot 05$ ). Co-expression of PDX-1 or Glut2 with insulin was observed frequently in the $\mathrm{HGF}^{+}$ groups (Fig. 4). Interestingly, co-expression of c-Kit with insulin which is frequently observed in fetal rat islet cell development (Yashpal et al. 2004) was also detected after 1 week in the differentiation culture (Fig. 4).

\section{HGF alters the expression of genes in epithelial monolayers}

Given that HGF is a potent differentiation factor, we examined at the mRNA level whether or not HGF altered the expression of insulin or glucagon, the expression of the progenitor marker c-Kit and the transcription factors PDX-1 and Ngn3 at the mRNA level. With the addition of the growth factor HGF, the monolayers had increased expression of insulin and glucagon mRNA, a 6.5- and 2 -fold increase respectively in comparison with control monolayers (Fig. 5). However, the increase was only significant for insulin mRNA levels $(P<0 \cdot 001)$. A similar expression pattern was observed in the $\mathrm{HGF}^{-}$group with slightly lower expression than that of the $\mathrm{HGF}^{+}$group (Fig. 5). We also examined the expression of PDX-1 and Ngn3, transcription factors importantly expressed during pancreatic development (Pang et al. 1994, Sander \& German 1997, McKinnon \& Docherty 2001, Gu et al. 2003). Upon closer inspection, PDX-1 levels were only different between the control and $\mathrm{HGF}^{-}$groups such that there was a 2-fold reduction in PDX-1 mRNA detected in the $\mathrm{HGF}^{-}$group. Ngn3 was highly expressed in the control monolayers and weakly in both the $\mathrm{HGF}^{+}$and $\mathrm{HGF}^{-}$groups (Fig. 5). The expression of c-Kit mRNA reached a maximum in the control and $\mathrm{HGF}^{+}$group, but was also expressed in the $\mathrm{HGF}^{-}$group (Fig. 5).

\section{HGF promotes proliferation of epithelial monolayers}

Given that HGF is a regulator of cell proliferation (Beattie et al. 1996, Burr et al. 1998, Kokuzawa et al. 2003), we also tested the ability of HGF to regulate proliferation of epithelial monolayers derived from postnatal rat islets. In the control monolayers, a highly proliferative population of cells was detected with a $34 \pm 3 \%$ BrdU-labeling index (Wang et al. 2004). There was a lower proliferative capacity present in both the $\mathrm{HGF}^{+}$and $\mathrm{HGF}^{-}$groups in comparison with the control monolayers (Fig. 6A; $P<0 \cdot 01)$. HGF was able to stimulate a higher proliferation as a 1.8 -fold increase in comparison with cells with no HGF treatment was observed (18 \pm 2 vs $10 \pm 3 \%$ ); however, this increase was not statistically significantly different. Double immunostaining for BrdU and c-Kit in the $\mathrm{HGF}^{+}$group showed that c-Kit-positive cells frequently labeled for BrdU after 1 week of culture (Fig. 6B).

\section{HGF increases insulin content and secretion of epithelial monolayers}

We also examined the ability of epithelial monolayers treated with HGF to re-store and secrete insulin. In control monolayers, basal insulin release was compromised such that insulin in the media was not detected. However, upon treatment with HGF, there was an up-regulation in basal insulin release such that $1.95 \mathrm{ng} / \mathrm{ml}$ insulin was released (Fig. 7). Furthermore, in the $\mathrm{HGF}^{+}$group there was a 3-fold increase in the insulin content of the cells in comparison with the insulin content present in cells within the control monolayers $(0 \cdot 49 \pm 0 \cdot 18$ vs $0 \cdot 15 \pm 0 \cdot 01 \mathrm{ng} / \mu \mathrm{g}$ DNA; $P<0 \cdot 01)$. No difference in basal insulin release was observed between the $\mathrm{HGF}^{+}$and $\mathrm{HGF}^{-}$groups; however, there was 2 -fold increase in the insulin content in the $\mathrm{HGF}^{+}$group, significantly higher than that of the $\mathrm{HGF}^{-}$ insulin levels (Fig. 7; $P<0 \cdot 05$ ). Glucose stimulation studies showed that insulin-expressing cells present in the $\mathrm{HGF}^{+}$ and $\mathrm{HGF}^{-}$groups failed to respond to a $22 \mathrm{mM}$ glucose challenge.

\section{Discussion}

HGF has previously been shown to be a potent regulator of $\beta$-cell function and to maintain mature $\beta$-cell phenotypes (Otonkoski et al. 1994, 1996, Hayek et al. 1995). Previous studies have demonstrated that islets in vitro on a type I collagen gel transdifferentiate into pancreatic ductal cells (Yuan et al. 1996, Wang et al. 2001), but the factors which confer morphogenetic stability on isolated islets and the possibility of reversing an islet from ductal phenotype has remained limited (Wang et al. 2004). Given the rather 

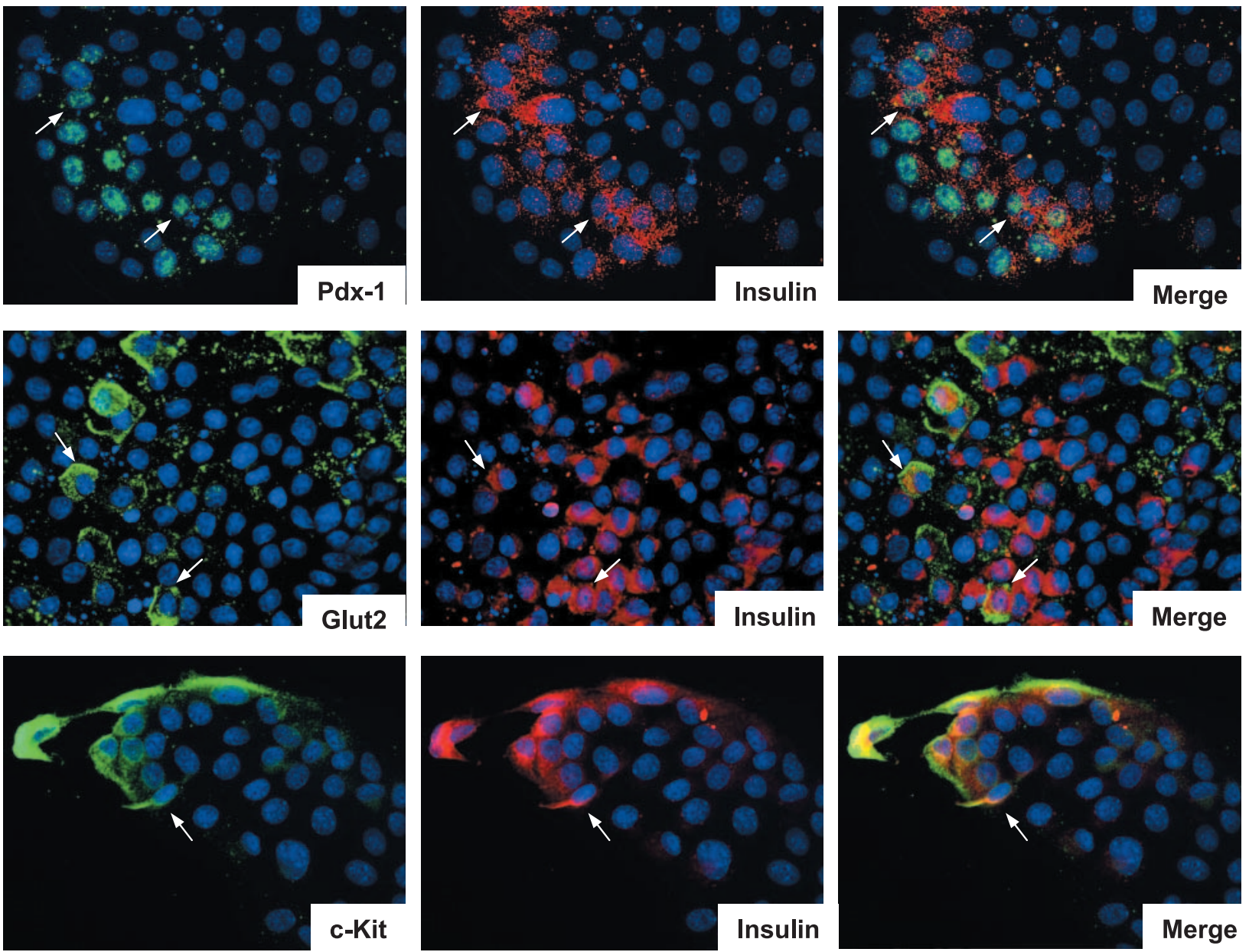

Figure 4 Co-expression of PDX-1, Glut2 or c-Kit (FITC) with insulin tetromethyl rhodamine isothiocynate (TRITC) in epithelial monolayers cultured with HGF $\left(\mathrm{HGF}^{+}\right)$for a week determined by double immunofluorescence staining. Nuclei were counterstained by DAPI (arrows indicate the co-localization). Original magnification $\times 400$.

poor stability of islets in vitro, the present study has demonstrated that peptide growth factors such as HGF may guide the differentiation of putative islet progenitors such as c-Kit-expressing cells into insulin-expressing cells. Taken together, this study suggests that HGF is involved in proliferation, differentiation and the partial restoration of $\beta$-cell function and islet cell phenotype.

The reversibility of transdifferentiation has been reported in other systems (Erenpreisa \& Roach 1996). Stability of cellular phenotype is most likely regulated by cell-cell interactions or cell-substrate interactions, thus a disruption in cellular milieu may induce cells to change their commitment. Growth factors may essentially play a bi-potential role in either mediating the transdifferentiation of one cell phenotype into another or the reversibility of transitory unstable changes in cell phenotype. Our present studies have been concerned with the latter effects of growth factor function. Given the repertoire of cellular events that HGF regulates in the pancreas, it is plausible that HGF acts as an insulinotropic and $\beta$-celldifferentiating factor within our own monolayer system (Otonkoski et al. 1994, 1996, Hayek et al. 1995, Beattie et al. 1996, Mashima et al. 1996, 1999, Gahr et al. 2002). This role in our study is exemplified by insulin- and glucagon-expressing cell phenotypes subcultured in a modified defined differentiation medium (Wang et al. 2004) showing an increased proportion of insulin- and glucagon-expressing cells in comparison with the control monolayers and an increase in their mRNA expression with the addition of HGF.

Mashima et al. (1996, 1999) had previously revealed that, in combination with activin A, HGF is capable of directing the differentiation of the rat acinar cell line, AR42J, into insulin-producing cells with an altered expression profile of genes, including the up-regulation of islet cell genes. In the present study, monolayers that were cultured with a defined differentiation medium had a decreased expression profile of early embryonic $\beta$-cell 


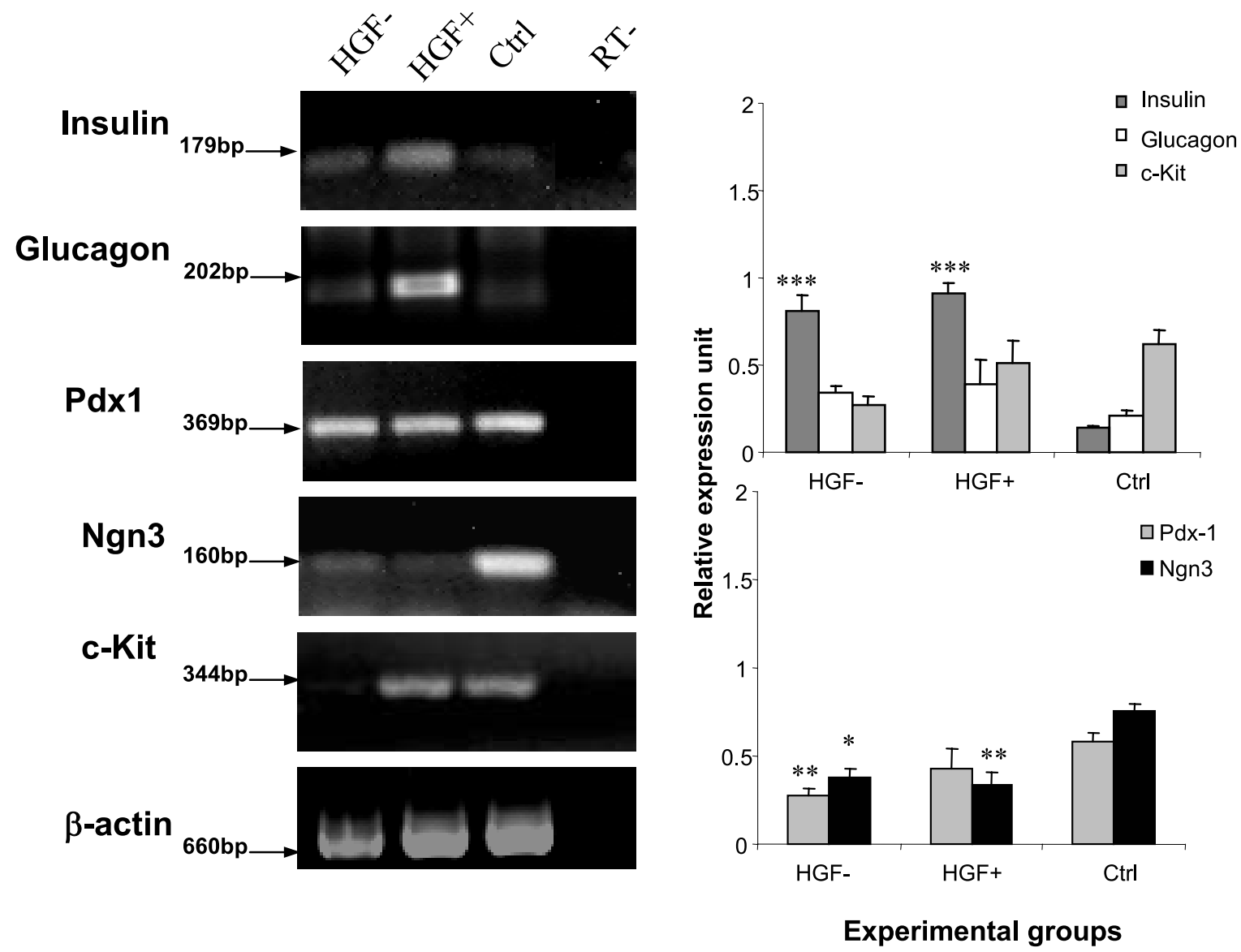

Figure 5 Semi-quantitative RT-PCR analysis of endocrine signals, developmental transcription factors and c-Kit mRNA in epithelial monolayers cultured with $\mathrm{HGF}\left(\mathrm{HGF}^{+}\right)$or without $\mathrm{HGF}\left(\mathrm{HGF}^{-}\right)$and control monolayers (Ctrl) on a type I collagen matrix for a week. Data are given as means \pm S.E.M. ${ }^{*} P<0 \cdot 05,{ }^{* *} P<0 \cdot 01,{ }^{* *} P<0 \cdot 001$.

transcription factors such as PDX-1 and Ngn3 in both $\mathrm{HGF}^{+}$and $\mathrm{HGF}^{-}$groups, but an increase in insulin mRNA expression. In addition, HGF supplementation also results in a significant increase in the proportion of Glut2 immunopositive cells and a slight increase in PDX-1 expression, two important mature $\beta$-cell markers. Furthermore, we showed that HGF promotes the restoration of $\beta$-cell function identified by increased insulin content and basal insulin release but there was an inability of the $\mathrm{HGF}^{+}$group to respond to a high glucose challenge.

Transdifferentiation involves cell proliferation and the appearance of a multipotential transdifferentiated intermediate cell (Yuan et al. 1996, Wang et al. 2001) which can express markers characteristic of several alternative phenotypes. This intermediate cell type may be c-Kitexpressing cells which either co-localize with the ductal marker cytokeratin 20 (Wang et al. 2004) or upon stimulation with HGF co-localize with insulin. c-Kit-expressing cells during early embryonic rat pancreatic development in our recent findings were shown to frequently co-localize with insulin and later lose their insulin expression in postnatal life, suggesting that mature $\beta$-cells may derive from these c-Kit-expressing cells and can be expanded in epithelial monolayer culture (Wang et al. 2004, Yashpal et al. 2004). c-Kit-expressing cells can also be immunomagnetically sorted from these monolayers and under the appropriate environmental cues can re-express insulin mRNA (Wang et al. 2004). Interestingly, in this study, we have revealed that HGF enhances the proliferative capacity of our monolayer system in comparison with $\mathrm{HGF}^{-}$ and augments the frequent co-localization of c-Kit with BrdU. Thus HGF may be responsible for directing a greater number of cells along their differentiation pathway towards a mature insulin-producing $\beta$-cell. Thus these results have demonstrated that it may be possible to expand a population of multipotential cells and then induce guided differentiation to a desired phenotype - in this case a mature insulin-producing $\beta$-cell.

The ability to manipulate and reconstitute physiological processes has tremendous clinical applications and is likely to play a relevant role in cell therapy. Our study has demonstrated that HGF is a potent growth factor that is 

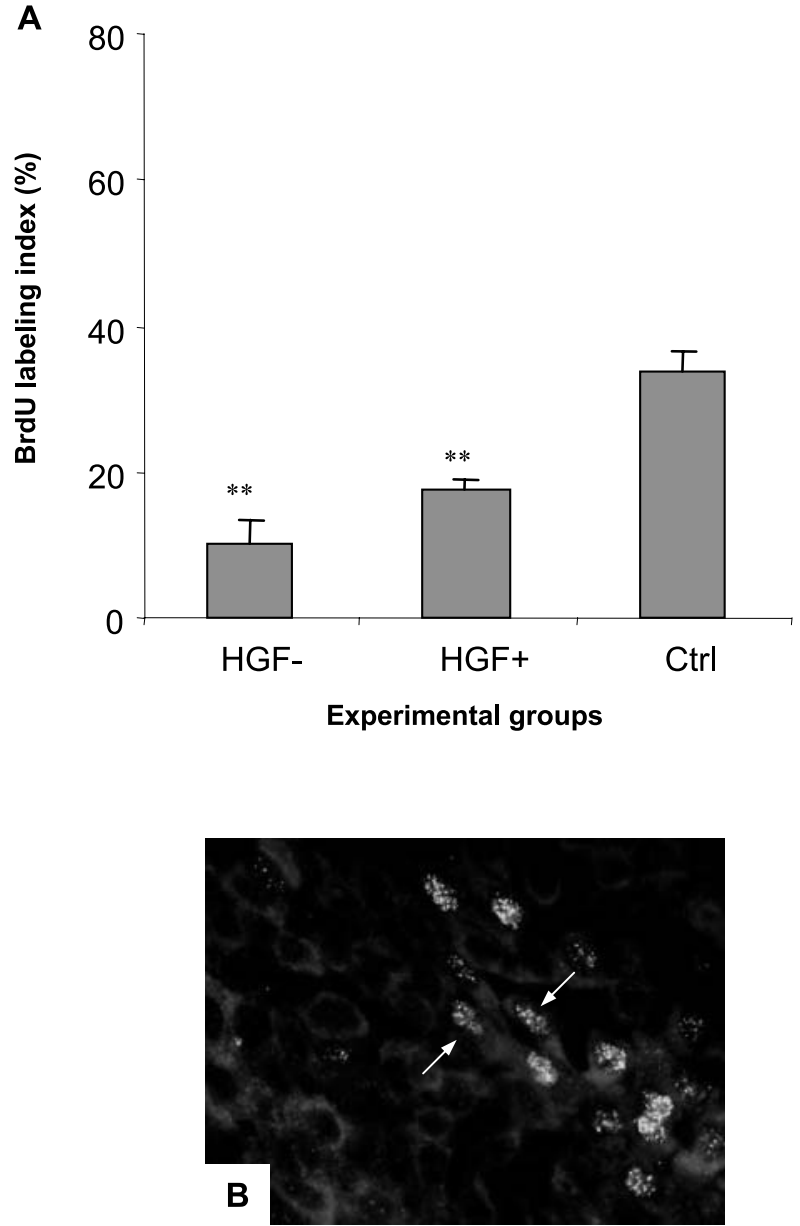

Figure 6 (A) BrdU-labeling index of epithelial monolayers cultured with $\mathrm{HGF}\left(\mathrm{HGF}^{+}\right)$or without $\mathrm{HGF}\left(\mathrm{HGF}^{-}\right)$and control monolayers $(\mathrm{Ctrl})$ on a type I collagen matrix for a week. ${ }^{*} P<0 \cdot 01$ compared with control. (B) Double immunostaining of BrdU (FITC) and c-Kit (TRITC) in epithelial monolayers cultured with HGF for a week. Arrows indicate the c-Kit-proliferating cells. Date are given as means \pm S.E.M. Original magnification $\times 400$.

capable of partial restoration of $\beta$-cell function in epithelial monolayers and a stimulator of $\beta$-cell differentiation. However, it must be noted that complete restoration of $\beta$-cell function does not occur as no islet clusters form, and furthermore these cells respond poorly to a glucose challenge. Taken together, these results suggest that in vitro differentiation protocols must be further examined and may be facilitated by the addition of exogenous HGF to create conditions that match embryonic and fetal development such as the polarization/presence of other growth factors and suitable extracellular matrix proteins. This study clearly revealed that along with HGF's known pancreatic roles, this peptide growth factor may also prove to be a useful tool to augment islet mass from transdifferentiated or undifferentiated cell types such as c-Kitexpressing cells derived from the pancreas. Although
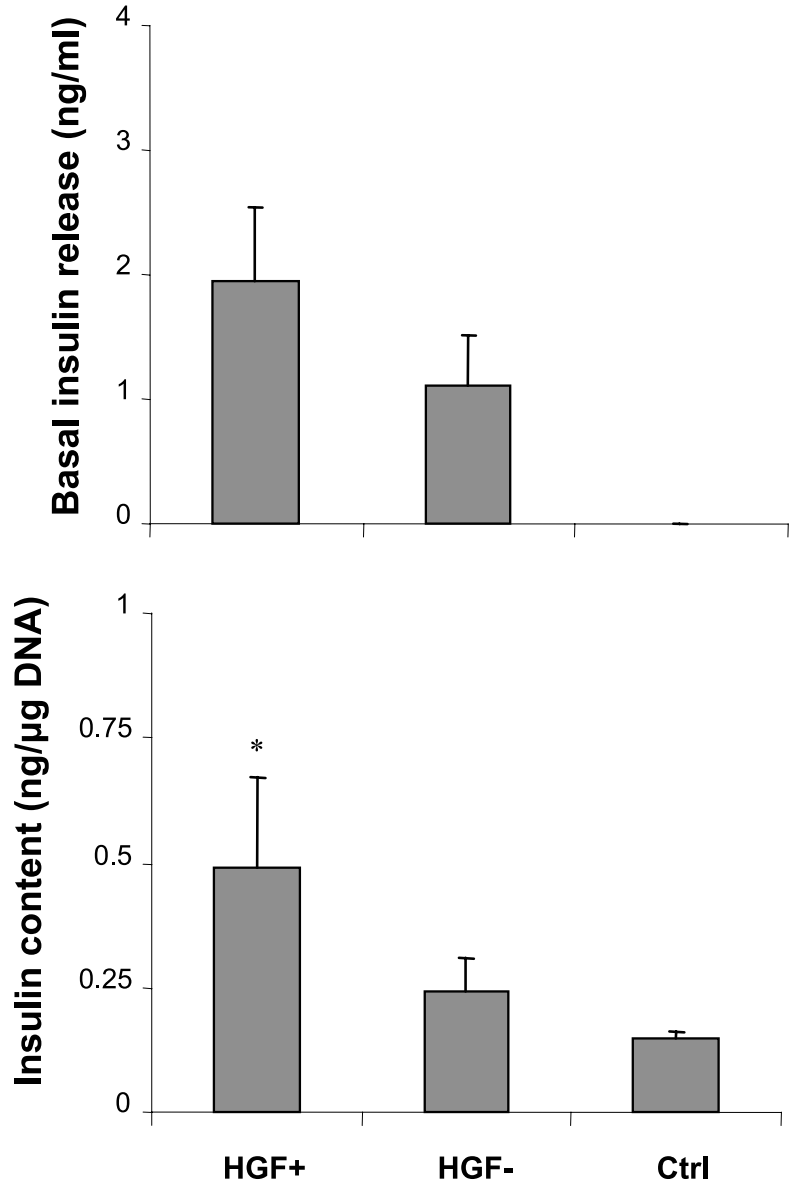

Experimental groups

Figure 7 Functional analysis of differentiated insulin-expressing cells in epithelial monolayers cultured with $\mathrm{HGF}\left(\mathrm{HGF}^{+}\right)$or without HGF $\left(\mathrm{HGF}^{-}\right)$and control monolayers (Ctrl) on a type I collagen matrix for a week. Statistical analysis showed significant differences in basal insulin release and insulin content in both the $\mathrm{HGF}^{+}$and $\mathrm{HGF}^{-}$groups in comparison with control monolayers. Date are given as means \pm S.E.M.

further improvement is needed for the complete functional restoration and maturation in vitro, these results suggest and demonstrate that HGF supplementation offers a promising culture condition for the in vitro maturation of cytokeratinexpressing cells that express islet progenitor markers into insulin-expressing cells.

\section{Acknowledgements}

This work was supported by grants from the Canadian Institute of Health Research (CIHR). R W is supported by a University Faculty Award from the Natural Sciences and Engineering Research Council of Canada (NSERC). 


\section{References}

Arias AE \& Bendayan M 1993 Differentiation of pancreatic acinar cells into duct-like cells in vitro. Laboratory Investigation 69 518-530.

Beattie GM, Rubin JS, Mally MI, Otonkoski T \& Hayek A 1996 Regulation of proliferation and differentiation of human fetal pancreatic islet cells by extracellular matrix, hepatocyte growth factor, and cell-cell contact. Diabetes 45 1223-1228.

Beattie GM, Montgomery AM, Lopez AD, Hao E, Perez B, Just ML, Lakey JR, Hart ME \& Hayek A 2002 A novel approach to increase human islet cell mass while preserving beta-cell function. Diabetes 51 435-439.

Bonner-Weir S, Taneja M, Weir G, Tatarkiewicz K, Song KH, Sharma A \& O’Neill JJ 2000 In vitro cultivation of human islets from expanded ductal tissue. PNAS 97 7999-8004.

Burr AW, Toole K, Chapman C, Hines JE \& Burt AD 1998 Anti-hepatocyte growth factor antibody inhibits hepatocyte proliferation during liver regeneration. Journal of Pathology 185 298-302.

Calvo El, Boucher C, Pelletier G \& Morisset J 1996 Ontogeny of hepatocyte growth factor and c-met/hof receptor in rat pancreas. Biochemical and Biophysical Research Communications 229 257-263.

Dai C, Li Y, Yang J \& Liu Y 2003 Hepatocyte growth factor preserves beta cell mass and mitigates hyperglycaemia in streptozotocin-induced diabetic mice. Journal of Biological Chemistry $200327827080-27087$.

Erenpreisa J \& Roach HI 1996 Epigenetic selection as a possible component of transdifferentiation. Further study of the commitment of hypertrophied chondrocytes to become osteocytes. Mechanisms of Aging and Development 287 165-182.

Gahr S, Merger M, Bollheimer LC, Hammerschmied CG, Scholmerich J \& Hugl SR 2002 Hepatocyte growth factor stimulates proliferation of pancreatic beta-cells particularly in the presence of subphysiological glucose concentrations. Journal of Molecular Endocrinology 28 99-110.

Garcia-Ocana A, Vasavada RC, Cebrian A, Reddy V, Takane KK, Lopez-Talavera JC \& Stewart AF 2001 Transgenic overexpression of hepatocyte growth factor in the beta-cell markedly improves islet function and islet transplant outcomes in mice. Diabetes $\mathbf{5 0}$ 2752-2762.

Gherardi E \& Stoker M 1991 Hepatocyte growth factor-scatter factor: mitogen, motogen and met. Cancer Cells 3 227-232.

Gu G, Brown JR \& Melton DA 2003 Direct lineage tracing reveals the ontogeny of pancreatic cell fates during mouse embryogenesis. Mechanisms of Development 120 35-43.

Hall PA \& Lemoine NR 1992 Rapid acinar to ductal transdifferentiation in cultured human exocrine pancreas. Journal of Pathology 1992166 97-103.

Hayek A, Beattie GM, Cirulli V, Lopez AD, Ricordi C \& Rubin JS 1995 Growth factor/matrix-induced proliferation of human adult beta-cells. Diabetes 44 1458-1460.

Kokuzawa J, Yoshimura S, Kitajima H, Shinoda J, Kaku Y, Iwama T, Morishita R, Shimazaki T, Okano H, Kunisada T \& Sakai N 2003 Hepatocyte growth factor promotes proliferation and neuronal differentiation of neural stem cells from mouse embryos. Molecular and Cellular Neurosciences 24 190-197.
McKinnon CM \& Docherty K 2001 Pancreatic duodenal homeobox-1, PDX-1, a major regulator of beta cell identity and function. Diabetologia 200144 1203-1214.

Mashima H, Shibata H, Mine T \& Kojima I 1996 Formation of insulin-producing cells from pancreatic acinar AR42J cells by hepatocyte growth factor. Endocrinology 137 3969-3976.

Mashima H, Yamada S, Tajima T, Seno M, Yamada H, Takeda J \& Kojima I 1999 Genes expressed during the differentiation of pancreatic AR42J cells into insulin-secreting cells. Diabetes 48 304-309.

Nakano M, Yasunami Y, Maki T, Kodama S, Ikehara Y, Nakamura T, Tanaka M \& Ikeda S 2000 Hepatocyte growth factor is essential for amelioration of hyperglycemia in streptozotocin-induced diabetic mice receiving a marginal mass of intrahepatic islet grafts. Transplantation $69214-221$.

Otonkoski T, Beattie GM, Lopez AD \& Hayek A 1994 Use of hepatocyte growth factor/scatter factor to increase transplantable human fetal islet cell mass. Transplant Proceedings 263334.

Otonkoski T, Cirulli V, Beattie M, Mally MI, Soto G \& Rubin JS 1996 A role for hepatocyte growth factor/scatter factor in fetal mesenchyme-induced pancreatic beta-cell growth. Endocrinology 137 3131-3139.

Pang K, Mukonoweshuro C \& Wong GG 1994 Beta cells arise from glucose transporter type 2 (Glut2)-expressing epithelial cells of the developing rat pancreas. PNAS 91 9559-9563.

Sander M \& German MS 1997 The beta cell transcription factors and development of the pancreas. Journal of Molecular Medicine $\mathbf{7 5}$ 327-340.

Wang R \& Rosenberg L 1999 Maintenance of $\beta$-cell function and survival following islet isolation requires re-establishment of the islet-matrix relationship. Journal of Endocrinology 163 181-190.

Wang R, Bouwens L \& Kloppel G 1994 Beta-cell proliferation in normal and streptozotocin-treated newborn rats: site dynamics and capacity. Diabetologia 37 1088-1096.

Wang R, Li J \& Rosenberg L 2001 Factors mediating the transdifferentiation of islets of Langerhans to duct epithelial-like structures. Journal of Endocrinology 171 309-318.

Wang R, Li J \& Yashpal N 2004 Phenotypic analysis of c-Kit expression in epithelial monolayers derived from postnatal rat pancreatic islets. Journal of Endocrinology 182 113-122.

Wang X, Zhou Y, Kim HP, Song R, Zarnegar R, Ryter SW \& Choi AM 2003 Hepatocyte growth factor protects against hypoxia/reoxygenation-induced apoptosis in endothelial cells. Journal of Biological Chemistry 279 5237-5243.

Yashpal N, Li J \& Wang R 2004 Characterization of c-Kit and nestin expression during islet cell development in the prenatal and postnatal rat pancreas. Developmental Dynamics $229813-825$.

Yuan S, Rosenberg L, Paraskevas S, Agapitos D \& Duguid WP 1996 Transdifferentiation of human islets to pancreatic ductal cells in collagen matrix culture. Differentiation 61 67-75.

Zarnegar R \& Michalopoulos GK 1995 The many faces of hepatocyte growth factor: from hepatopoiesis to hematopoiesis. Journal of Cell Biology 129 1177-1180.

Received 9 April 2004

Accepted 22 June 2004

Made available online as an

Accepted Preprint 7 July 2004 